\title{
EFEKTIVITAS DAN EFISIENSI BIAYA PENDIDIKAN SELAMA MASA PANDEMI COVID - 19 PADA SMA DI KABUPATEN MANDAILING NATAL
}

\author{
Sulhan Hamid H Lubis, Eka Daryanto, Osbert Sinaga \\ Universitas Negeri Medan Sumatera Utara, Indonesia \\ Email: sulhanhamid@gmail.com, ekadaryanto@unimed.ac.id, \\ osbertsinaga@unimed.ac.id
}

\begin{abstract}
Abstrak
Adanya pandemi covid 19 memaksa pemerintah mengeluarkan kebijakan pembelajaran daring. Hal ini tentu akan berpengarus signifikan pada pemanfaatan dan pengalokasian biaya pendidikan yang telah dianggarkan dan dituangkan dalam Rencana Kerja Sekolah baik pada RKAS yang bersumber dari dana BOS maupun dana Sumbangan Pembinaan Pendidikan yang bersumber dari orang tua siswa. Penelitian ini bertujuan untuk melihat secara langsung pemanfaatan dana pendidikan selama masa covid 19 apakah sudah efektif dan efisien. penelitian ini menggunakan metode kualitatif deskriptif. Data yang diperoleh dari 24 kepala sekolah bendaraha pada SMA di kabupaten Mandailing Natal tahun 2021 dengan menyebarkan angket melalui google format dan wawancara. Ditemukan bahwa sekolah tidak mempersiapkan diri secara maksimal untuk memanfaatkan dana secara efektif dan efisien. Hal ini juga tidak terlepas dari ketidakpastian sampai kapan berakhir pembelajaran daring karena informasi yang berubah-ubah (tergantung status daerah masing-masing berdasarkan level kedaruratan) tentang jadwal pembelajaran tatap muka terbatas dan adaptasi kehidupan baru. Namun pengalokasian biaya pendidikan di setiap sekolah memenuhi 8 Standar Nasional Pendidikan walapun pengalokasian tiap SNP tidak merata karena kebutuhan berbeda. Adanya pengalihan pembiayaan dari RKAS yang telah disusun diawal tahun karena adanya perubahan sistem pembelajaran dan perubahan juknis BOS. Pengalihan kegiatan ekstrakurikuler, penggandaan soal ujian ditiadakan atu dikurangi dan dialihkan pada kegiatan pemeliharaan dan penggantian, pembelian alat dan bahan kesehatan seperti thermogun, handsanitizer, masker dan disinfektan. Pembiayaan selama pandemi Covid-19 secara umum mengalami perubahan yang cukup signifikan dalam hal pengalokasian bukan pada jumlah dana yang dikeluar. Pada masa normal ada estrakurikuler pramuka, ekstrakurikuler olahraga dan kegiatan OSIS dialihkan menjadi dana pemeliharaan dan penggantian. Biaya langganan dan jasa seperti listrik mengalami penurunan tapi muncul biaya baru seperti paket data bagi guru dan tenaga kependidikan. Biaya pengembangan pendidik dan tenaga kependidikan juga mengalami kenaikan karena adanya pengembangan kompetensi yang diikuti guru secara daring.
\end{abstract}

Kata Kunci: Efektivitas; Efisiensi; Pembiayaan pendidikan masa pandemi Covid - 19

$\begin{array}{ll}\text { How to cite: } & \text { Lubis,S,H,H., Daryanto, E., \& Sinaga, O., (2021) Efektivitas dan Efisiensi Biaya Pendidikan Selama } \\ & \text { Masa Pandemi Covid }-19 \text { Pada SMA Di Kabupaten Mandailing Natal, Syntax Idea, 3(12), } \\ & \text { https://doi.org/10.36418/syntax-idea.v3i12.1680 } \\ \text { E-ISSN: } & \text { 2684-883X } \\ \text { Published by: } & \text { Ridwan Institute }\end{array}$




\section{Abstract}

The existence of the covid 19 pandemic forced the government to issue an online learning policy. This will certainly have a significant impact on the utilization and allocation of education costs that have been budgeted and outlined in the School Work Plan both on RKAS sourced from BOS funds and Education Development Contribution funds sourced from parents of students. This study aims to see firsthand the utilization of education funds during the Covid 19 period whether it has been effective and efficient. This study uses descriptive qualitative methods. Data obtained from 24 principals bendaraha at high school in Mandailing Natal district in 2021 by spreading the questionnaire through Google format and interviews. It found that schools were not fully prepared to utilize funds effectively and efficiently. It is also inseparable from the uncertainty until when online learning ends because of the changing information (depending on the status of each region based on the level of emergency) about limited face-to-face learning schedules and new life adaptations. But allocating the cost of education in each school meets the 8 National Standards of Education even though the allocation of each SNP is uneven because of differentneeds. The transfer of financing from RKAS that has been prepared at the beginning of the year due to changes in the learning system and changes in BOS juknis. The transfer of extracurricular activities, the doubling of exam questions is eliminated and diverted to maintenance and replacement activities, the purchase of medical devices and materials such as thermoguns, handsanitizers, masks and disinfectants. Financing during the Covid19 pandemic in general experienced significant changes in allocating rather than in the amount of funds spent. In normal times there are scouting, extracurricular sports and student council activities diverted into maintenance and reimbursement funds. The cost of subscriptions and services such as electricity has decreased but new costs such as data plans for teachers and education personnel have fallen. The cost of developing educators and education personnel has also increased due to the development of competencies followed by teachers online.

Keywords: Effectiveness; Efficiency; Education financing during the Covid-19 pandemic

Received: 2021-11-22; Accepted: 2021-12-05; Published: 2021-12-20

\section{Pendahuluan}

Untuk meningkatkan kualitas sumber daya manusia peranan pendidikan sangat dibutuhkan. Sumber daya manusia sebagai sebuah output pendidikan diharapkan mampu menghadapi lingkungan kerja dan memiliki kontribusi terhadap pembangunan sosial, ekonomi. Hal ini dilakukan dengan meningkatkan pengetahuan, keterampilan, skil, sikap dan produktivitas. Terlebih lagi bagi masyarakat luas, pendidikan itu dikatakan bermanfaat apabila membawa kemajuan bagi khalayak ramai dan mempunyai pengaruh pada pesatnya pertumbuhan ekonomi (Dacholfany, 2017).

Masyarakat masih mempersepsikan pendidikan sebagai sebuah investasi yang menguntungkan dibanding dengan investasi lainnya. (Becker, 2009) menyatakan bahwa konsep human capital merupakan modal yang ada pada diri manusia untuk 
menghasilkan pendapatan dan output lainnya untuk manfaat jangka panjang. Anggapan ini muncul seiring semakin bertambanya jumlah peserta didik di setiap negara dengan bertambahnya jumlah penduduk dan pada sisi lain pendidikan sudah merupakan kebutuhan dasar manusia

Era globalisasi membawa ilmu pengetahuan dan teknologi berkembang pesat sehingga menuntut persaingan yang kompetitif dan mendorong peningkatan kualitas melalui pendidikan. Lingkungan masyarakat yang berpendidikan juga mendorong agar anak-anaknya memiliki pendidikan yang lebih tinggi. Kondisi merupakan hal yang lumrah karena pendidikan masih merupakan jalan atau cara melahirkan generasi yang maju. Dibutuhkan biaya yang tidak sedikit untuk mempertahankan dan meningkatkan mutu Pendidikan (Neolaka, 2019).

Tuntutan ini mengharuskan penyelenggara pendidikan memberikan pelayanan terbaik agar mampu mengelola pendidikan sehingga konsumen (masyarakat) merasa puas. Sejumlah sumber daya dibutuhkan dalam mendukung dan mencapi tujuan yang diharapkan. Salah satu sumber daya yang perlu diperhatikan dalam penyelenggaraan pendidikan yaitu aspek pembiayaan. Semakin banyak kebutuhan dan tuntutan terhadap pendidikan maka penyelenggara pendidikan akan menetapkan pembiayaan yang semakin tinggi. Biaya dalam bentuk anggaran merupakan unsur utama terlaksananya kegiatan dan kebutuhan nyata yang tidak dapat dihindari (Irwanto, 2018).

Lancar tidaknya penyelenggaraan pendidikan akan sangat tergantung pada jumlah dana yang tersedia dengan dana yang dibutuhkan. Biaya dalam penyelenggaraan pendidikan memiliki kedudukan yang strategis. Hal tersebut dapat dilihat dari dua fungsi biaya dalam pendidikan yaitu; pertama sebagai alat menganalisis berbagai asfek finansial pendidikan dan sebagi parameter untuk memproyeksi gejala sistem pendidik. (Rahman \& Kashem, 2017). Oleh sebab itu efisiensi dan efektivitas biaya pendidikan merupakan tanggungjawab bersama dalam penyelenggaran pendidikan. Dengan demikian biaya pendidikan yang berasal dari pemerintah, orang tua maupu masyarakat dapat dipertanggungjawabkan secara jujur dan amanah. Begitu juga proses pembelajaran dapat menghasilkan pendidikan yang bermutu dan lulusan yang berdaya saing. Efisiensi dan Efektivitas biaya pendidkan diharapkan mampu menghasilkan sumber daya manusia yang tepat guna dan berhasil guna. Kunci keberhasilan pembangunan pendidikan terletak pada kemampuan sumber daya manusia mengelola dana yang tersedia dengan berpatokan pada kebutuhan dasar pendidikan dan skala prioritas program sekolah setiap tahun dan perencanaan yang berkesinambungan (Suhelayanti et al., 2020).

Dalam hal ini perlu membedakan antara efisiensi dan efektivitas biaya pendidikan. Menurut (Johnes, Portela, \& Thanassoulis, 2017) mengatakan Efficiency refers to 'doing things right' (efisiensi mengacu pada melakukan sesuatu dengan benar). sedangkan effectiveness relates to 'doing the right things' (efektivias mengacu pada melakukan hal yang benar). Dalam konteks pendidikan, penggunaan sumber daya yang efisien (baik keuangan atau kemampuan dasar siswa) terjadi ketika output yang pendidikan (seperti hasil ujian atau nilai tambah) yang dihasilkan pada tingkat sumber 
daya yang paling rendah; penggunaan sumber daya yang efektif memastikan bahwa gabungan hasil dari pendidikan yang diinginkan oleh masyarakat tercapai.

Sementara itu menurut (Lubis, Effendi, \& Prayudi, 2020) Effectiveness refers to the accomplishment of objectives, whereas efficiency refers to the resource used to achieve those objectives (Efektivitas mengacu pada pencapaian tujuan, sedangkan efisiensi mengacu pada sumber daya yang digunakan untuk mencapai tujuan tersebut). Menurut (Jauhari \& Ridwan, 2017), pengertian efektifitas adalah seberapa baik pekerjaan yang dilakukan, sejauh mana orang menghasilkan keluaran sesuai dengan yang diharapkan. (Massie, Saerang, \& Tirayoh, 2018); Efisiensi merujuk pada sejumlah konsep yang terkait pada kegunaan pemaksimalan serta pemanfaatan sumber daya

Keuangan dalam arti pembiayaan sekolah harus dikelola sebaik mungkin berdasarkan prinsip-prinsip keuangan agar dapat dimanfaatkan secara optimal. Peran aktif stakeholder baik dari internal maupun eksternal sangat diharapkan dalam pengelolaan (manajemen) pembiayaan ini. Hal ini akan berpengaruh pada optimalisasi dana yang tersedia dengan kebutuhan yang dibutuhkan oleh lembaga pendidikan. Jumlah dana yang berlebih akan mengurangi efisiensi pengelolaan keuangan, sedangkan jumlah dana yang minim akan mengurangi kinerja sumber daya seperti kinerja guru dan karyawan, pemanfaatan fasilitas sekolah dan lain sebagainya (Rahmadoni, 2018).

Prinsip-prinsip pengelolaan pendanaan pendidikan tertuang pada Peraturan Pemerintah Republik Indonesia no 48 Tahun 2008 tentang Pendanaan Pendidikan yaitu prinsip keadilan, efisiensi, transparansi dan akuntabilitas publik. Keempat prinsip ini harus dimulai dari perencanaan, realisasi penerimaan dan pengeluaran dana pendidikan, pengawasan dan pemeriksaan serta pertanggungjawaban (Hidayat, 2019).

Pada pasal 51 PP no 48 tahun 2008 juga disebutkan bahwa pendanaan pendidikan bersumber dari pemerintah, pemerintah daerah dan masyarakat. Untuk tingkatan SMA sumber pendanaan berasal dari dana BOS Pusat pada tahun 2021 nominalnya mulai Rp 1.500 .000 - 3.470.000/. besaran bervariasi tergantung karakteristik daerah masingmasing dan ini merupakan ketetapan kementerian pendidikan dan kebudayaan riset dan teknologi. Senada dengan peraturan pemerintah tentang pengelolaan pendanaan, prinsip-prinsip pengelolaan dan BOS juga dilakukan berdasarkan prinsip fleksibilitas, efektivitas, efisiensi dan akuntabilitas (Akbar, 2015).

Selain sumber dana yang berasal dari BOS, untuk tingkat SMA juga masih dibolehkan memungut biaya dari orang tua siswa atau yang disebut dengan SPP (Sumbangan Pembinaan Pendidikan). Besaran dana SPP merupakan kesepatan orang tua siswa dengan lembaga pendidikan setelah sekolah mengajukan proposal anggaran pembiayaan yang tidak ditampung pada dana BOS. Di luar itu sekolah juga masih dapat menerima hibah atau bantuan pihak lain yang tidak mengikat dan untuk kemajuan pendidikan di lembaga tersebut (Subarna, 2014).

Pada umumnya SMA di kabupaten Mandailing Natal hanya mengandalkan pengelolaan pembiayaan pendidikan yang bersumber dari dana BOS dan SPP. Setiap sekolah menerima jumlah dana BOS yang diterima setiap sekolah berbeda-beda tergantung jumlah siswa yang ada di sekolah tersebut. Penetapan besaran dana SPP juga 
sangat bervariasi tergantung kesanggupan orang tua dan jumlah kegiatan sekolah yang akan dibiayai. Sekolah dengan jumlah siswa yang banyak dan kemampuan orang tua di atas rata-rata akan mudah mengalokasikan pembiayaan pendidikan. Namun sebalik sekolah dengan jumlah siswa yang sedikit dan kemampuan orang tua yang menengah ke bawah akan kesulitan merancang kegiatan sekolah untuk peningkatan mutu pembelajaran dan kegiatan sekolah lainnya. Hal inilah yang mengharuskan sekolah harus memaksimalkan pengelolaan keuangan dengan perlunya menganalisis efisiensi dan efektivitas biaya pendidikan agar penggunaan anggaran tepat guna dan tepat sasaran (Prasojo, 2017).

Berdasarkan observasi yang peneliti lakukan pada SMA Negeri 2 Plus Panyabungan pada tanggal 27 September 2021 saat pandemi covid 19 dan pemerintah masih mengeluarkan kebijakan pembelajaran daring, adanya pengalihan anggaran pelaksanaan ujian dan kegiatan ekstrakurikuler dengan pengadaan sarana sanitasi dan kebersihan seperti tempat cuci tangan, sabun atau hand sanitizer dan disinfektan.

Hasil wawancara dengan bendahara SMA Negeri 2 Plus Panyabungan Kab Mandailing Natal mengungkapkan bahwa pemanfaatan dana pendidikan selama masa covid 19 harus dapat diefektifkan dan digunakan seefisien mungkin, namun karen masa covid 19 merupakan situasi yang insidentil sehingga sekolah tidak mempersiapkan diri secara maksimal untuk memanfaatkan dana secara efektif dan efisien. Hal ini juga tidak terlepas dari ketidakpastian sampai kapan berakhir pembelajaran daring karena informasi yang berubah-ubah (tergantung status daerah masing-masing berdasarkan level kedaruratan) tentang jadwal pembelajaran tatap muka terbatas dan adaptasi kehidupan baru.

Pembiayaan pendidikan merupakan salah satu cakupan penting pengelolaan pendidikan. Hal ini diyakini memberikan pengaruh pada peningkatan kualitas pendidikan itu sendiri. Penelitian ini akan menganalisis biaya pendidikan di SMA kabupaten Mandailing Natal dilihat dari aspek efektivitas dan efisiensi.

\section{Metode Penelitian}

Dalam menghasilkan suatu rekomendasi kebijakan pembiayaan pendidikan harus memiliki landasan konseptual yang kuat. Selain itu juga didukung data dan informasi obyektif dan aktual yang diperoleh dari lapangan. Penelitian melalui pendekatan deskriptif-kuantitatif dan kualitatif perlu dilakukan untuk mengungkapkan beragam informasi dan permasalahan dan kaitannya dengan analisis biaya ditinjau dari efektivitas dan efisiensi biaya pendidikan.

Data sumber biaya, alokasi dana penggunaan didapatkan dari pendekatan kuantitatif. Sedangkan untuk mengindentifikasi dan mendalami data dan informasi langsung dan tidak langsung dilakukan dengan pendekatan kualitatif.

Penelitian ini dilaksanakan di Kabupaten Mandailing Natal pada tingkat SMA baik negeri maupun swasta dengan populasi sebanyak 24 Sekolah. Walaupun demikian, penelitian ini memiliki asumsi terhadap wilayah penelitian dan substansi yang diteliti. Hal ini berakibat pada penentuan sumber penelitian tidak mengharuskan semua sekolah 
yang ada di Kabupaten Mandailing Natal menjadi responden penelitian. Selain kondisi yang tidak memungkinkan dilihat dari biaya dan waktu penelitian ini, peneliti juga memiliki keterbatasan jumlah personalia untuk menjadi responden penelitian.

\section{Hasil dan Pembahasan}

1. Efektivitas dan Efisiensi biaya pendidikan masa pandemi Covid-19 Tahun Pelajaran 2020-2021

Penggunaan dana pada SMA di Kabupaten Mandailing Natal pada masa pandemi covid-19 pada tahun pelajaran 2021-2021 mengalami perubahan jika dilihat pada 8 Standar Nasional Pendidikan (1. Standar pengembangan kompetensi lulusan, 2. pengembangan Standar Isi, 3. Pengembangan standar proses, 4. Pengembangan Pendidik dan Tenaga Kependidikan, 5. Pengembangan Sarana dan Prasarana Sekolah, 6. Pengembangan Standar Pengelolaan, 7. Standar Pembiayaan dan, 8. Pengembangan dan Implementasi Sistem Penilaian. (Anonym: 2021). Hal ini dapat digambarkan dari 3 jenis pembiayaan;

a. Jenis Biaya Operasional

1) Kesejahteraan tenaga pendidik dan kependidikan

Secara umum, SMA di kabupaten Mandailing Natal tidak melakukan perubahan penganggaran selama masa covid-19 dalam anggaran insentif tambahan bagi guru PNS/GTY per orang setiap bulan, Insentif tambahan bagi tenaga administrasi di sekolah per orang per bulan. Honor yang diterima guru bantu/sukarelawan/ honor daerah dari sekolah per bulan, Biaya yang dialokasikan dari sekolah untuk pakaian seragam guru per orang, Biaya yang dialokasikan dari sekolah untuk pakaian seragam tenaga administrasi per orang.

Selama masa covid-19 tidak ada honor bagi guru untuk kelebihan jam mengajar dari sekolah, tidak ada alokasi uang lembur dari sekolah bagi tenaga administrasi sekolah per jam dan, tidak ada biaya perjalanan dari sekolah untuk proses mutasi/promosi per guru. Hal yang sama juga terjadai dalam anggaran hadiah hari raya dari sekolah untuk guru (per orang) dan hadiah hari raya dari sekolah untuk tenaga administrasi, sekolah tidak menganggarkannya.

2) Peningkatan Profesi/Diklat

Terjadi perubahan anggaran yang cukup signifikan dalam Biaya khusus sekolah untuk diklat peningkatan kemampuan professional secara daring bagi guru per orang per tahun. Karena pada APBS Sekolah tingkat SMA di kabupaten Mandailing Natal hampir tidak menganggarkan sebelumnya. Perubahan pola pembelajaran dan evaluasi pembelajaran menyebabkan sekolah harus mengadakan pelatihan pembelajaran daring bagi guru

Adanya larangan berkerumun dan harus menjaga jarak, biaya khusus sekolah untuk diklat peningkatan kemampuan professional secara luring bagi guru per orang per tahun hampir tidak ada dan dipindahkan ke sistem daring. 
Begitu juga dengan biaya diklat bagi kepala sekolah per orang per tahun, Biaya diklat bagi tenaga administrasi sekolah per orang per tahun.

Sementara itu biaya sekolah untuk pelaksanaan kegiatan KKG/MGMP per guru per tahun dan biaya sekolah untuk pelaksanaan kegiatan MKKS per tahun tetap dianggarkan karena masih bisa dilaksanakan secara daring hanya saja dikurangi volumenya karena frekuensinya tidak seperti dianggarkan diawal.

3) Penyelenggaraan KBM

Pembiayaan sekolah untuk penyediaan buku bahan ajar pada tahun ajaran 2020-2021 tetap dianggarkan pada masa covid-19. Namun biaya penyediaan bahan praktikum IPA atau IPS dan bahan praktik keterampilan dihapuskan dan alokasikan untuk kegiatan lain. Selanjutnya biaya sekolah untuk pengembangan kurikulum muatan lokal dan pengembangan diri dan biaya sekolah untuk pelaksanaan remedial juga ditiadakan karena pelaksanaan pembelajaran menggunakan sistem daring dan tidak ada praktik baik pembelajaran maupun pelaksanaan ujiann.

4) Penilaian

Dalam aspek penilaian terjadi variasi yang dilakukan oleh sekolah tingkat menengah atas di Kabupaten Mandailing Natal. 20 Sekolah masih menganggarkan biaya sekolah untuk ulangan umum baik secara teori maupun praktek. Begitu juga biaya sekolah untuk ujian akhir baik tertulis ataupun praktik. Sekolah tetap meng copy soal ujian kemudian siswa menjemput soal ke sekolah dan mengembalikan lembar jawaban sesuai waktu yang ditentukan. Sedangkan 3 sekolah seperti SMA Negeri Panyabungan, SMA Negeri 2 Plus Panyabungan, SMA Negeri 3 Panyabungan, melakukan ujian daring melalui google form atau LMS. SMA Negeri 1 Panyabungan Timur melakukan model ujian campuran dimana ulangan harian dan tugas-tugas menggunakan kertas dan ujian mid semester dan ujian akhir semester, ujian kenaikan kelas dan ujian akhir sekolah variasi ujian menggunakan aplikasi.

Sementara itu secara umum tidak ada sekolah yang mengeluarkan biaya pengembangan dan penilaian tes diagnostik dan pengukuran IQ, EQ baik sebelum dan selama masa pandemi covid-19. Berbeda halnya biaya untuk pembelian buku raport tetap dianggarkan seperti tahun sebelumnya. Biaya pemilihan jurusan bagi siswa baru hanya dilakukan beberapa sekolah seperti SMA Negeri 1 Panyabungan, SMA Negeri 2 Plus Panyabungan dan SMA Negeri 1 Natal sedangkan sekolah-sekolah lain siswa memilih sendiri jurusan yang diinginkan selama masih ada kuota. Untuk biaya test minat dan bakat dalam melanjutkan ke perguruan tinggi tidak dilakukan sekolah secara kelembagaan hanya saja sekolah memfasilitasi dengan pihak penyedia jasa (lembaga psikotest) jika ada siswa yang mau mengikutinya.

Setelah dihapuskannya Ujian Nasional pemerintah melakukan Asessmen Nasional Berbasis Komputer (ANBK). Dalam hal ini sekolah mengeluarkan 
biaya pelaksanaan ujian seperti honor proktor, teknisi dan pengawas ujian baik pada kegiatan simulasi maupun pelaksanaan ujian.

5) Pemeliharaan dan penggantian

Dengan banyaknya efisiensi dana pada aspek di atas, maka dana dialokasikan sebelumnya dialihkan untuk kegiatan pemeliharaan dan penggantian. Setiap sekolah bervariasi tentang besaran dana yang direposisi. Dana yang dialihkan berkisar antara 10-25\% dari dana yang tersedia. Biaya yang mengalami penambahan signifikan pada biaya sekolah untuk perawatan bangunan sekolah dan perawatan perabot kantor. Sementara biaya penggantian alat IPA, penggantian alat keterampilan yg rusak malah mengalami penurunan karena tidak ada penggunaan yang rutin. Untuk biaya penggantian buku pelajaran yg rusak dan pembabatan rumput halaman sekolah tidak mengalami perubahan namun ada penambahan pada pemeliharaan taman. Selama covid-19 muncul biaya sekolah untuk sarana kesehatan dan pencegahan covid- 19 seperti tempat cuci tangan, sabun atau handsanitizer, tissue, disinfektan dan thermogun. Begitu juga pembelian masker bagi warga sekolah dan tamu yang berkunjung.

6) Daya dan Jasa

Biaya sekolah untuk listrik per bulan selama masa pandemi covid 19 mengalami penurunan yang signifikan karena berkurangnya penggunaan arus listrik terutama di SMA Negeri 2 Plus Panyabungan dan SMA IT Al Husnayain yang menerapkan siswa boarding school. Biaya penggunaan air (ledeng) tidak mengalami penurunan yang berarti karena hampir $85 \%$ atau 20 sekolah tidak menggunakan air PAM tapi air sumur. Begitu juga biaya sekolah untuk telephon tidak mengalami penurunan karena secara umum sekolah di Mandailing Natal tidak lagi mengaktifkan telepon kantor atau faksimile. Sekolah yang menggunakan sistem paket pada jaringan internet tidak mengalami penurunan atau kenaikan. Hanya sekolah yang memakai sistem pulsa yang mengalami peningkatan pengeluaran karena pembelajaran daring disarankan dilakukan di sekolah dan biaya internet ditanggung oleh sekolah.

Sekolah juga mengediakan paket data untuk guru dan tenaga administrasi per bulan. Besaran biaya paket data sangat bervariasi tergantung kebijakan sekolah masing-masing. Seperti SMA Negeri 1 Panyabungan memberikan biaya paket data sebesar Rp 50.000 untuk masing-masing pendidik dan tenaga pendidik sedangkan di SMA Negeri 2 Plus Panyabungan menyediakan paket data sebesar 100.000 perbulan. Sedangkan biaya paket data untuk siswa per bulan disediakan oleh kemendikbud.

7) Kesiswaan

Untuk kegiatan kesiswaan hampir semua mengalami efisiensi karena tidak adanya pembelajaran tatap muka. Beberapa kegiatan yang rutin dibiaya sekolah seperti pembinaan OSIS, pramuka, olahraga. Kesenian, pelaksanaan Porseni, Cerdas Cermat tingkat sekolah, Olimpiade Sains tingkat sekolah, 
pembinaan KIR, Peringatan hari raya besar, kegiatan Pesantren kilat per siswa, dan kegiatan Orientasi Siswa baru tidak jadi dianggarkan dan dialihkan ke kegiatan lain seperti yang dijelaskn pada aspek penggantian dan pemeliharaan sarana dan prasarana.

Beasiswa dari kemendikbudristek bagi siswa kurang mampu yang lebih sering kita kenal dengan Kartu Indonesia Pintar tetap dilaksanakan sama seperti masa normal. Sejak SMA menjadi kewenangan provinsi, belum pernah ada Beasiswa dari pemda Propinsi per siswa per tahun (BOS Propinsi). Hanya saja tahun pelajaran 2021-2022 ada dana BOS dari Provinsi yang bernama Bantuan Operasional Pendidikan (BOP) SMA/SMK dan SLB tapi bukan berupa beasiswa tapi biaya operasional sekolah. Sejak tahun 2016 SMA sederajat dimutasikan ke provinsi praktis tidak ada beasiswa dari pemda Kab./Kota begitu juga BOS pendamping.

8) Supervisi

Biaya untuk kegiatan supervisi oleh kepala sekolah secara umum tidak dianggarkan oleh sekolah karena dianggap bagian dari tupoksi kepala sekolah. Sama halnya dengan biaya untuk kegiatan supervisi oleh pengawas sekolah tidak ada alokasi dananya. Hanya saja beberapa sekolah membuat pelatihan yang menghadirkan pengawas sekolah untuk memastikan kelengkapan dokumen atau perangkat pembelajaran.

b. Jenis Biaya Investasi

1) Sarana Prasarana

Untuk sekolah baik negeri maupun swasta tidak ada anggaran untuk biaya pembebasan tanah untuk lahan sekolah. Hanya saya sekolah swasta menganggarkan dari sumber lain seperti pendapatan bersih selama 1 tahun dan ini tidak dibukukan secara manajemen sekolah tapi manajemen yayasan atau perguruan. Sama halnya dengan biaya untuk pembangunan ruang kelas baru, ruang tata usaha, ruang kepala sekolah, ruang wakil kepala sekolah, ruang guru, ruang perpustakaan, laboratorium IPA, laboratorium bahasa, laboratorium seni, laboratorium komputer, ruang keterampilan tidak ada dianggarkan oleh sekolah negeri tapi sekolah swasta tetap menganggarkan ini tergantung kemampuan sekolah dan bersumber dari uang yayasan.

Secara umum SMA di Kabupaten Mandailing Natal tidak ada menginvestasikan biaya untuk, pembangunan lapang olahraga, ruang serbaguna, ruang ibadah, pembangunan kamar kecil /WC, ruang Ekstrakurikuler, ruang BK. Hanya saja sekolah melakukan pemeliharaan dan perbaikan ringan untuk sarana tersebut. Beberapa sekolah seperti SMA Negeri 1 Nagajuang, SMA Negeri 1 Muara Batanggadis dan SMA Negeri 1 Natal melakukan pembangunan rumah ibadah dengan dana yang bersumber dari bantuan orang tua siswa dan masyarakat. Alokasi ini tidak ada dicantumkan dalam keuangan sekolah dan dibukukan pada laporan keuangan tersendiri. 
Meskipun masih dalam masa covid-19, sekolah masih menganggarkan biaya untuk pembelian buku Teks Utama, buku Perpustakaan, buku sumber, buku pelengkap. Seperti ketentuan BOS pada umumnya sekolah menganggarkan pembelian buku $20 \%$ dari total dana BOS. Hanya saja jika sekolah sudah memiliki rasio satu buku satu siswa maka sekolah boleh tidak harus mengalokasikan sebesarr $20 \%$. Mengingat sebagian besar SMA di Kabupaten Mandailing Natal sudah mengimplementasikan Kurikulum 2013 berkisar 3-4 tahun, maka pembelian buku oleh sekolah hanya antara 5-15\%.

Sekolah-sekolah juga tidak mengalokasikan biaya pembelian alat peraga dan alat Praktik sesuai RKAS awal namun mengalami penyesuaian karena tidak adanya pembelajaran tatap muka dan pengalihan dana untuk kesehatan warga sekolah. Namun sekolah masih tetap melakukan pembelian LCD, komputer, dan perabot sekolah karena dianggap sesuatu yang penting untuk kelengkapan sarana sekolah.

Untuk pembelian alat protokol kesehatan, rata-rata sekolah membeli thermogun atau alat pendeteksi suhu tubuh. Sebagai alat kelengkapan protokol kesehatan, thermogun ini menjadi alat yang wajib dimiliki sekolah dalam masa pandemi covid-19.

2) Tenaga

Secara umum sekolah negeri tidak mengeluarkan biaya untuk pengadaan tenaga pendidik dan tenaga kependidikan. Lazimnya calon tenaga pendidik atau kependidikan memasukkan lamaran ke sekolah yang dituju dan di seleksi sesuai kebutuhan sekolah. Satu-satunya sekolah yang melaksanakan test tertulis dan pengumuman terbuka luas pada tingkat SMA di kabupaten Mandailing Natal hanyalah SMA IT Al Husnayain. Sekolah ini rutin mengadakan rekrutmen tenaga pendidik dan kependidikan di awal semester. Lain hal dengan SMA Negeri 2 Plus Panyabungan, pengumuman penerimaan di share di media sosial dan diseleksi via wawancara dan kegiatan ini tidak ada dianggarkan dalam biaya pendidikan di sekolah tersebut.

\section{c. Jenis Biaya Personal}

Biaya personal dikeluarkan seperti gaji, tunjangan dan pendapatan lainnya. Pengalokasian gaji bagi pendidik dan tenaga kependidikan dimasukkan pada dana BOS dan SPP. Untuk guru PNS sudah barang tentu di danai dari pemerintah dan mereka hanya mendapatkan tunjangan jabatan yang dialokasikan dari dana SPP seperti tunjangan kelancaran tugas wakil kepala sekolah, wali kelas, pembina pramuka, Pembina OSIS, Pembina O2SN, FLS2N dan kegiatan lain. Sementara untuk guru non PNS ada 2 kategori penggajian yaitu guru dengan status Guru Tidak Tetap digaji dari APBD Provinsi Sumatera Utara dan Guru Komite Sekolah yang di danai dari SPP. Untuk tunjangan dan pendapatan lainnya juga berlaku bagi guru non PNS. Untuk tenaga kependidikan yang sudah memiliki NUPTK gaji dialokasikan dari dana BOS dan yang belum memiliki NUPTK mendapatkan gaji dari uang SPP. 
Berbeda halnya dengan sekolah swasta, penggajian dan tunjangan pendidik dan tenaga kependidikan dialokasikan pihak yayasan dari dana BOS dan uang SPP. Besaran gaji tergantung kemampuan sekolah dan lamanya bertugas. Sekolah swasta seperti SMA IT Al Husnayain juga menerapkan penggajian dengan melihat masa kerja (gaji berkala).

\section{Kesimpulan}

Sesuai dengan hasil penelitian dan pembahasan tetang Analisis Pembiayaan Pendidikan berdasarkan Efektivitas dan Efisiensi di SMA Kabupaten Mandailing Natal yang dilakukan pada 24 Sekolah dapat disimpulkan sebeagai berikut ini: (1.) Pengalokasian biaya pendidikan di setiap sekolah memenuhi 8 Standar Nasional Pendidikan (Standar pengembangan kompetensi lulusan, pengembangan Standar Isi, Pengembangan standar proses, Pengembangan Pendidik dan Tenaga Kependidikan, Pengembangan Sarana dan Prasarana Sekolah, Pengembangan Standar Pengelolaan, Standar Pembiayaan dan, Pengembangan dan Implementasi Sistem Penilaian) namun pengalokasian tidak merata karena kebutuhan tidak merata. Seperti kebutuhan SNP Standar Isi dan Pengelolaan mendapatkan porsi yang sedikit karena pembelajaran dilaksanakan secara daring dan ujian banyak dilakukan secara online. (2.) Adanya pengalihan pembiayaan dari RKAS yang telah disusun diawal tahun karena adanya perubahan sistem pembelajaran dan perubahan juknis BOS. Pengalihan kegiatan ekstrakurikuler, penggandaan soal ujian ditiadakan atu dikurangi dan dialihkan pada kegiatan pemeliharaan dan penggantian, pembelian alat dan bahan kesehatan seperti thermogun, handsanitizer, masker dan disinfektan. (3.) Pembiayaan selama pandemi Covid-19 secara umum mengalami perubahan yang cukup signifikan dalam hal pengalokasian bukan pada jumlah dana yang dikeluar. Pada masa normal ada estrakurikuler pramuka, ekstrakurikuler olahraga dan kegiatan OSIS dialihkan menjadi dana pemeliharaan dan penggantian. Biaya langganan dan jasa seperti listrik mengalami penurunan tapi muncul biaya baru seperti paket data bagi guru dan tenaga kependidikan. Biaya pengembangan pendidik dan tenaga kependidikan juga mengalami kenaikan karena adanya pengembangan kompetensi yang diikuti guru secara daring. 


\section{BIBLIOGRAFI}

Akbar, Adimas Hazidar. (2015). Implementasi Peraturan Bupati Sukoharjo Nomor 19 Tahun 2011 Tentang Pendanaan Pendidikan Dasar Dan Pendidikan Menengah (Studi Kasus: Sekolah Di Kabupaten Sukoharjo). Universitas Negeri Semarang.Google Scholar

Becker, Gary S. (2009). Human capital: A theoretical and empirical analysis, with special reference to education. University of Chicago press. Google Scholar

Dacholfany, M. Ihsan. (2017). Inisiasi Strategi Manajemen Lembaga Pendidikan Islam Dalam Meningkatkan Mutu Sumber Daya Manusia Islami Di Indonesia Dalam Menghadapi Era Globalisasi. At-Tajdid: Jurnal Pendidikan Dan Pemikiran Islam, 1(01). Google Scholar

Irwanto, Irwanto. (2018). Efektivitas manajemen sumber daya manusia dalam peningkatan mutu sekolah: studi implementatif di SD Mutiara Parahyangan. UIN Sunan Gunung Djati Bandung. Google Scholar

Jauhari, Rahman, \& Ridwan, Ridwan. (2017). Efisiensi dan Efektivitas Penggunaan Modal Kerja Pada Koperasi Syariah di Kota Banda Aceh Tahun 2011-2015. Syiah Kuala University. Google Scholar

Johnes, Jill, Portela, Maria, \& Thanassoulis, Emmanuel. (2017). Efficiency in education. Journal of the Operational Research Society, Vol. 68, pp. 331-338. Taylor \& Francis. Google Scholar

Lubis, Hilda Ariska Br, Effendi, Ihsan, \& Prayudi, Ahmad. (2020). Pengaruh Tingkat Modal Kerja Terhadap Harga Saham Pada Perusahaan Otomotif \& Komponen Yang Terdaftar Di Bei Periode 2014-2018. Jurnal Ilmiah Manajemen Dan Bisnis (Jimbi), 1(2). Google Scholar

Massie, Novela Irene Karly, Saerang, David P. E., \& Tirayoh, Victorina Z. (2018). Analisis Pengendalian Biaya Produksi Untuk Menilai Efisiensi Dan Efektivitas Biaya Produksi. Going Concern: Jurnal Riset Akuntansi, 13(03). Google Scholar

Neolaka, Ir Amos. (2019). Isu-isu kritis pendidikan: utama dan tetap penting namun terabaikan. Prenada Media. Google Scholar

Prasojo, Lantip Diat. (2017). Implementasi Fungsi Supervisor dan Kepala Madrasah di Madrasah Ibtidaiyah Muhammadiyah Tamiang Ujung Gading Kabupaten Pasaman Barat Provinsi Sumatera Barat. Google Scholar

Rahmadoni, Jefril. (2018). Isu Global Manajemen Pembiayaan Pendidikan di SD Indonesian Creative School Pekanbaru. JMKSP (Jurnal Manajemen, Kepemimpinan, Dan Supervisi Pendidikan), 3(2), 161-169. Google Scholar

Rahman, Mohammad Mafizur, \& Kashem, Mohammad Abul. (2017). Carbon 
emissions, energy consumption and industrial growth in Bangladesh: Empirical evidence from ARDL cointegration and Granger causality analysis. Energy Policy, 110, 600-608. Google Scholar

Subarna, Barna. (2014). Pendidikan Gratis Sekolah Menengah Pertama:: Antara Harapan Dan Kenyataan. Deepublish. Google Scholar

Suhelayanti, Suhelayanti, Aziz, M. Ridwan, Sari, Dian Cita, Safitri, Meilani, Saputra, Syifa, Purba, Sukarman, Revida, Erika, Purba, Ramen A., Muharlisiani, Lusy Tunik, \& Simarmata, Janner. (2020). Manajemen Pendidikan. Yayasan Kita Menulis. Google Scholar

\section{Copyright holder:}

Sulhan Hamid H Lubis, Eka Daryanto, Osbert Sinaga (2021)

\section{First publication right:}

Syntax Idea

This article is licensed under:

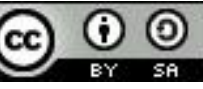

